http://jmscr.igmpublication.org/home/ ISSN (e)-2347-176x ISSN (p) 2455-0450

crossref DOI: https://dx.doi.org/10.18535/jmscr/v8i2.135

Journal Of Medical Science And Clinical Research

\title{
Prospective Study to Compare Conventional Radiotherapy with Hypofractionated Radiotherapy in Locally Advanced Carcinoma of Oral Cavity
}

\author{
Authors \\ Sanjay Kumar Verma ${ }^{1 *}$, S.N.Prasad ${ }^{2}$, M.W.Raza ${ }^{3}$ \\ ${ }^{1}$ Resident, ${ }^{2}$ Professor and Head, ${ }^{3}$ Assistant Professor \\ JK Cancer G.S.V.M. Medical College Kanpur Uttar Pradesh \\ *Corresponding Author \\ Sanjay Kumar Verma
}

\begin{abstract}
Background: India accounts for higher incidence of oral and oropharyngeal cancer. For early stage chemoradiation or surgery are equally effective. For advanced stage chemoradiotherapy is the treatment of choice. Conventional radiotherapy requires $2 G y$ per fraction, with 5 fraction per week. Accelarated repopulation sets in $4^{\text {th }}$ weeks of conventional radiotherapy. To overcome this effect hypofractionated radiotherapy may be useful. This study was designed to compare conventional radiotherapy with hypofractionated radiotherapy

Materials and Methods: Total 56 patients (28 patients in each arm)were selected from the cross section of patients registered at tertiary care hospital with histologically proven squamous cell carcinoma of oral cavity from Oct 2017 to July 2019.Data obtained from study was compared to find out differences in term of response, acute and chronic treatment realated toxicity

Results: $39.14 \%$ patients(9) in arm $A$ and 36\%(9) in arm B had complete response,56;52\%(13) in arm A and 48\%(12)had partial response in arm B,4.34\%(1) in arm A and 16\%(4) in arm B were lost to follow up

Conclusions: Hypofractionated radiotherapy has a comparable response to conventional radiotherapy with slight more acute and late but manageable treatment related toxicity with significantly reduced (3wks) treatment time.
\end{abstract}

\section{Introduction}

Head and neck cancer is the 7th most common type of cancer and $8^{\text {th }}$ most common cancer related death in the world, more than 8 lakhs new cases of head and neck cancer are diagnosed each year. In india head neck cancer is the most common cancer in men, About 1.93 lakhs new cases of head neck cancer are diagnosed and 1.14 lakhs deaths occurred due to head neck cancer per year in India. India contributes up to $15.6 \%$ of the global cancer burden and $12.1 \%$ of global cancer deaths. ${ }^{[1]}$

Chemoradiotherapy has been identified as a standard therapeutic method in head and neck cancers. ${ }^{[2-3]}$ Work of Maciejewski ${ }^{[4]}$ and Withers ${ }^{[5] \text {, }}$ showed that with increasing overall time the total dose to cure a tumour of the head and neck area had to be raised. This was attributed to 
repopulation, which may not be important until the third week of a course of treatment. Hypofractionated regimen reduces the overall treatment time were therefore investigated with the aim of reducing the time in which cellular repopulation could occur. To determine the Dose of radiation necessary to overcome the effects of tumor regeneration have been attempted in several studies. Withers et al analyzed that clonogens of tumor undergo an accelerated repopulation after a certain period of time, and when repopulation sets in, an additional $0.6 \mathrm{~Gy}$ is required per day of therapy beyond repopulation. ${ }^{[6]}$ It was estimated that this phenomenon of accelerated repopulation begins in the fourth week of a conventionally fractionated schedule, based on a retrospective analysis of local control rates in tonsillar carcinomas achieved at different international centers using a variety of fractionation schedules. $^{[7]}$

Sanghera et al. ${ }^{[8]}$ conducted a study of 81 patients with squamous cell carcinoma of larynx, oropharynx, oral cavity, and hypopharyngeal cancer received hypofractionated radiotherapy to a dose of 55 Gy in 20 fractions with concurrent chemotherapy. The 2-year local control rate was $75.4 \%$. The 2 -year OS rate was $71.6 \%$, and the 2year Disease Free Survival rate was $68.6 \%$.

Roy et al. ${ }^{[9]}$ study of 60 patients with biopsyproven squamous cell cancer of oral cavity, oropharynx, hypopharynx, and larynx (AJCC, 2010 Stage II to IVB), who received either hypofractionated ( $\operatorname{arm} \mathrm{B} n=30$ ) or conventional fractionation ( $\operatorname{arm~A~} n=30$ ) radiotherapy, with or without concurrent chemotherapy, Total dose in armA was 70 Gy in 35 fractions over 7 weeks.In arm B, total dose of 55 Gy in 20 fractions over 4weeks. Comparable tumor control in patients with HNSCC. $68 \%$ in conventional arm (Arm A) achieved a complete response (CR) and 60\% in hypofractionated arm (Arm B) had a CR. Late toxicity of grade 2 or higher was greater in hypo fractionated arm. The median Overall Survival was 18 months in conventional arm versus 17 months in hypo fractionated arm. The hypo fractionated regimen was associated with increased but tolerable acute and late morbidities.

The reduction in number of fractions and treatment time allows more efficient use of resources which can help avoid long waiting times in a busy center, but routine use of this hypofractionated schedule needs further studies. Hypofractionation is an alternative to conventional regimens with a shorter treatment time but with concerns about the late toxicities. Its development should not be at the expense of decreased LRC or unacceptable late toxicity.

\section{Material and Methods}

In This study total 56 patients $(28$ for conventional arm A and 28 hypofractionated arm B)were registered between oct2017 to july2019 with histologically confirmed squamous cell carcinoma of oral cavity by biopsy. Patients accrued for study underwent pretreatment evaluation which included complete history, physical examination, complete systemic examination. Patients were assessed their general condition by KPS and BSA. Their hematological assessment was done by complete hemogram, biochemical assessment of kidney and liver function, radiological assessment. Dental prophylaxis was done. Patients were staged according to AJCC staging system 8th.Based on the above assessment the patients for the study were selected depending on histologically proven cases of Carcinoma, Karnofsky Performance Status > 70, locally advanced oral cavity cancer Patients informed consent was taken. Patients having any of the following conditions were excluded from the study: Prior radiation, surgery or chemotherapy for the disease, poor general condition with Karnofsky Performance Status of $<70$,pregnant or lactating patient, associated medical condition such as renal disease, liver disease or heart disease

And thus the patients fulfilling the Inclusion criteria and exclusion criteria were randomized into two Arms as followed: 
Arm A: Received RT as conventional fractionation (200cGy per fraction), 5 days a week, off cord after $46 \mathrm{~Gy} / 23$ fraction. A total of 70 Gy was given with concurrent Inj. Cisplatin $100 \mathrm{mg} / \mathrm{m}^{2} 3$ weekly on $\mathrm{d} 1$ and $\mathrm{d} 22$

Arm B: Received RT as hypofractionated (300cGy per fraction), 5 fraction a week, off card after $39 \mathrm{~Gy} / 13$ fraction. Total of $60 \mathrm{~Gy} / 20$ fraction with concurrent Inj.Cisplatin $100 \mathrm{mg} / \mathrm{m}^{2}, 3$ weekly $\mathrm{d}^{1}$ and $\mathrm{d}^{22}$

From the commencement of treatment, all the patients included in the study were carefully and regularly assessed weekly during treatment. Radiation reactions were assessed by Radiation Therapy Oncology Group (RTOG) criteria. Tumor response (both primary and nodal response) were assessed by RECIST (1.1) response criteria 2 months after completion of Radiotherapy. The major study endpoints were tumor response, acute and late toxicities.
Patients were followed monthly upto a minimum of 6 months .All the patients were followed up regularly on OPD basis for a period of at least 6 months, once every month after completion of the treatment. At every visit, each patients were clinically evaluated for local control of disease and treatment related complications. The patients were assessed for any evidence of distant metastasis during each follow up. On suspicion of any local recurrence, biopsy were taken for histopathology and correlated clinically. The data thus obtained was assessed, analyzed and compared to find out difference in all the groups in terms of tumor response, acute and late treatment related toxicity by using student $\mathrm{t}$ test/chi square test..

\section{Results}

Total 56 patients are taken in both arms for trial based on inclusion and exclusion criteria were randomized to arm A and arm B

\section{Observations and Results}

Table 1: Shows Number of Patients In Each Arm

\begin{tabular}{|l|c|c|c|}
\hline NUMBER OF PATIENTS & ENROLLED & $\begin{array}{c}\text { DEFAULTED } \\
\text { (EXCLUDED) }\end{array}$ & NET \\
\hline CRT ARM & 28 & 5 & 23 \\
\hline HRT ARM & 28 & 3 & 25 \\
\hline TOTAL & 56 & 8 & 48 \\
\hline
\end{tabular}

In our study total number of patient in each arm A A and 5 patients in arm B are defaulted from and arm B was 28, out of which 3 patients in arm treatments, So excluded from study. [Table: 1]

Table 2: Shows Age Wise Distribution of Patients

\begin{tabular}{|l|c|c|c|c|}
\hline \multirow{2}{*}{ Age (Years) } & \multicolumn{2}{|c|}{$\begin{array}{c}\text { Arm A (Conventional } \\
\text { Radiotherapy) } \\
(\mathrm{n}=23)\end{array}$} & \multicolumn{2}{c|}{$\begin{array}{c}\text { Arm B (hypofractionated } \\
\text { Radiotherapy) } \\
(\mathrm{n}=25)\end{array}$} \\
\cline { 2 - 5 } & No. & $\%$ & No. & $\%$ \\
\hline $21-30$ & 2 & 8.69 & 1 & 4 \\
\hline $31-40$ & 9 & 39.14 & 10 & 40 \\
\hline $41-50$ & 6 & 26.08 & 6 & 24 \\
\hline $51-60$ & 6 & 26.09 & 8 & 32 \\
\hline $61-70$ & 0 & 0 & 0 & 0 \\
\hline Total & 23 & 100 & 25 & 100 \\
\hline
\end{tabular}

Age wise distribution in Arm A was maximum in age group 31 to 40 years i.e. 9 (39.14\%), followed by in 41 to 50 years $6(26.08 \%), 51$ to 60 years 6 $(26.09 \%), 21$ to 30 years $2(8.69 \%)$. Whereas in
Arm B, maximum in the age group of 31 to 40 years $10(40 \%)$, in 51 to 60 years $8(32.00 \%)$ and in 41 to 50 years $6(24 \%)$ and 21 to 30 years 1 (4\%) each. [Table: 2] 
Table 3: Shows Stages (Group Stage) of Cancer in Patients

\begin{tabular}{|l|c|c|c|c|}
\hline \multirow{2}{*}{ Stages } & \multicolumn{2}{|c|}{$\begin{array}{c}\text { Arm A (CRT) } \\
(\mathrm{n}=23)\end{array}$} & \multicolumn{2}{c|}{$\begin{array}{c}\text { Arm B (HRT) } \\
(\mathrm{n}=25)\end{array}$} \\
\cline { 2 - 5 } & No. & $\%$ & No. & $\%$ \\
\hline III & 1 & 4.35 & 2 & 8 \\
\hline IVA & 22 & 95.65 & 23 & 92 \\
\hline Total & 23 & $100 \%$ & 25 & $100 \%$ \\
\hline
\end{tabular}

Stages wise distribution in arm A were maximum stage IVA $22(95.65 \%)$ and stage III $1(4.3 \%)$, were as in arm B maximum stage IVA 23 (92\%) and stage III $2(8 \%)$ Chi-square $=0.4508, \mathrm{df}=1, \mathrm{P}$ value $=0.2510$, not significant. [Table: 3$]$

Table 4: Duration of Treatment in Days

\begin{tabular}{|l|c|c|}
\hline DURATION & $\begin{array}{c}\text { CRT ARM } \\
(\mathrm{n}=23)\end{array}$ & $\begin{array}{c}\text { HRT ARM } \\
(\mathrm{n}=25)\end{array}$ \\
\hline AVERAGE DURATION & $55-56$ & $32-33$ \\
\hline
\end{tabular}

Average duration of treatment (in days) were 55 to 56 days in arm A and 32 to 33 days in arm B. [Table: 4]

Table 5: Shows Tumor Response 2 Month after Treatment Completion

\begin{tabular}{|c|c|c|c|c|}
\hline \multirow{2}{*}{$\begin{array}{l}\text { TUMOR RESPONSE 2MONTH } \\
\text { AFTER } \\
\text { COMPLETION }\end{array}$} & \multicolumn{2}{|c|}{$\begin{array}{c}\text { CRT ARM } \\
(\mathrm{n}=23)\end{array}$} & \multicolumn{2}{|c|}{$\begin{array}{c}\text { HRT ARM } \\
(\mathrm{n}=25)\end{array}$} \\
\hline & No. & $\%$ & No. & $\%$ \\
\hline CR & 9 & 39.14 & 9 & 36 \\
\hline PR & 13 & 56.52 & 12 & 48 \\
\hline SD & 00 & 0 & 00 & 0 \\
\hline PD & 00 & 0 & 00 & 0 \\
\hline $\mathrm{NO} F / \mathrm{U}$ & 1 & 4.34 & 4 & 16 \\
\hline DEATH & 0 & 0 & 0 & 0 \\
\hline TOTAL & 23 & 100 & 25 & 100 \\
\hline
\end{tabular}

Our study showed the response of the treatment in Arm A 9 patients (39.14\%) showed complete response, $13(56.52 \%)$ showed partial response, No patients showed progressive disease and stable disease in comparison to Arm B 9 patients (36\%) showed complete response, 12 patients (48\%) showed partial response, No patients showed progressive disease and stable disease 1 patient (4.34\%) in arm A and 4 patients (16\%) have no follow up. Chi-square $=1.76, \mathrm{df}=2, \mathrm{P}$ value $=$ 0.4148. [Table: 5].

Table: 6 Shows Acute Skin Reaction

\begin{tabular}{|l|c|c|c|c|}
\hline \multirow{2}{*}{ ACUTE SKIN REACTION } & \multicolumn{2}{|c|}{$\begin{array}{c}\text { CRT ARM } \\
(\mathrm{n}=23)\end{array}$} & \multicolumn{2}{c|}{$\begin{array}{c}\text { HRT ARM } \\
(\mathrm{n}=25)\end{array}$} \\
\cline { 2 - 5 } & No. & $\mathbf{\%}$ & No. & $\%$ \\
\hline G-0 & 0 & 0 & 0 & 0 \\
\hline G-I & 13 & 56.52 & 18 & 72 \\
\hline G-II & 6 & 26.08 & 7 & 28 \\
\hline G-III & 4 & 17.39 & 0 & 0 \\
\hline G-IV & 0 & 0 & 0 & 0 \\
\hline TOTAL & 23 & 100 & 25 & 100 \\
\hline
\end{tabular}

In Arm A acute dermatitis grade 1 was $56.52 \%$, grade $2-26.08 \%$ and grade 3 was $17.39 \%$ in comparison to in Arm B grade $1-72 \%$ grade $2-$
$28 \%$. Chi-square $=1.2, \mathrm{df}=1, \mathrm{P}$ value $=0.318$, not significant. [Table: 6] 
Table 7: Shows Acute Mucosal Toxicities

\begin{tabular}{|l|c|c|c|c|}
\hline \multirow{2}{*}{$\begin{array}{l}\text { ACUTE MUCOSAL } \\
\text { TOXICITIES }\end{array}$} & \multicolumn{2}{|c|}{$\begin{array}{c}\text { CRT ARM } \\
(\mathrm{n}=23)\end{array}$} & \multicolumn{2}{c|}{$\begin{array}{c}\text { HRT ARM } \\
(\mathrm{n}=25)\end{array}$} \\
\cline { 2 - 5 } & $\mathbf{N o .}$ & $\mathbf{\%}$ & $\mathbf{N o .}$ & $\mathbf{\%}$ \\
\hline G-0 & 0 & 0 & 0 & 0 \\
\hline G-I & 3 & 13.04 & 0 & 0 \\
\hline G-II & 17 & 73.91 & 23 & 92 \\
\hline G-III & 3 & 13.04 & 2 & 8 \\
\hline G-IV & 0 & 0 & 0 & 0 \\
\hline TOTAL & 23 & 100 & 25 & 100 \\
\hline
\end{tabular}

In Arm A the mucositis grade 1-13.04\%, grade 2 $73.91 \%$, grade $3-13.04 \%$ in comparison to Arm $\mathrm{B}$ the grade $1-0 \%$, grade $2-92 \%$, grade $3-8 \%$.
Ryle's tube in Arm A was 4 patients (16\%) and B 3 patients $(13 \%)$. Chi-square $=0.3265, \mathrm{df}=1, \mathrm{P}$ value $=0.2839$, not significant. [Table: 7$]$

Table 8: Shows Late Toxicity Evaluate after /at 6 months of Follow Up (Dryness of Mouth)

\begin{tabular}{|l|c|c|c|c|}
\hline \multirow{2}{*}{$\begin{array}{l}\text { GALIVARY } \\
\text { GLAND(DOM) }\end{array}$} & \multicolumn{2}{|c|}{$\begin{array}{c}\text { CRT ARM } \\
(\mathrm{n}=23)\end{array}$} & \multicolumn{2}{c|}{$\begin{array}{c}\text { HRT ARM } \\
(\mathrm{n}=25)\end{array}$} \\
\cline { 2 - 5 } & No. & $\mathbf{\%}$ & No. & \% \\
\hline G-0 & 0 & 0 & 0 & 0 \\
\hline G-I & 2 & 20 & 0 & 0 \\
\hline G-II & 3 & 30 & 2 & 25 \\
\hline G-III & 5 & 50 & 6 & 75 \\
\hline G-IV & 0 & 0 & 0 & 0 \\
\hline TOTAL & 10 & 100 & 8 & 100 \\
\hline
\end{tabular}

Only 10 patient in Arm A and 8 patient in Arm B completed 6 months of follow up. The late toxicity evaluated after/at 6 months of follow up, In arm A only 10 patients and arm B only 6 patients completed 6 months of follow up, In our study dryness of mouth in arm A grade 1 (20\%), grade $2(30 \%)$, grade $3(50 \%)$ in comparison to in Arm B grade $1(0 \%)$, grade $2(25 \%)$ and grade 3 $(75 \%)$. Chi-square $=1.901, \mathrm{df}=1, \mathrm{P}$ value $=$ 0.0840, not significant. [Table: 8]

Table 9: Shows Sub Cutaneous Fibrosis

\begin{tabular}{|l|c|c|c|c|}
\hline \multirow{2}{*}{$\begin{array}{l}\text { SUB CUTANEOUS } \\
\text { FIBROSIS }\end{array}$} & \multicolumn{2}{|c|}{$\begin{array}{c}\text { CRT ARM } \\
(\mathrm{n}=23)\end{array}$} & \multicolumn{2}{c|}{$\begin{array}{c}\text { HRT ARM } \\
(\mathrm{n}=25)\end{array}$} \\
\cline { 2 - 5 } & No. & $\mathbf{\%}$ & No. & $\%$ \\
\hline G-0 & 0 & 0 & 0 & 0 \\
\hline G-I & 3 & 30 & 0 & 0 \\
\hline G-II & 4 & 40 & 4 & 50 \\
\hline G-III & 3 & 30 & 4 & 50 \\
\hline G-IV & 0 & 0 & 0 & 0 \\
\hline TOTAL & 10 & 100 & 8 & 100 \\
\hline
\end{tabular}

Sub Cutaneous Fibrosis was in Arm A Grade 1 (30\%), Grade $2(40 \%)$, Grade $3(30 \%)$, Where as in Arm B grade $1(0 \%)$, grade $2(50 \%)$ and grade
$3(50 \%)$. Chi-square $=1.8, \mathrm{df}=1, \mathrm{P}$ value $=$ 0.089, not significant. [Table: 9]

Table 10: Shows Sub Mucosal Fibrosis

\begin{tabular}{|l|c|c|c|c|}
\hline \multirow{2}{*}{} & \multicolumn{2}{|c|}{$\begin{array}{c}\text { CRT ARM } \\
(\mathrm{n}=23)\end{array}$} & \multicolumn{2}{c|}{$\begin{array}{c}\text { HRT ARM } \\
(\mathrm{n}=25)\end{array}$} \\
\cline { 2 - 5 } & No. & $\%$ & No. & $\%$ \\
\hline G-0 & 0 & 0 & 0 & 0 \\
\hline G-I & 2 & 20 & 0 & 0 \\
\hline G-II & 5 & 50 & 3 & 37.5 \\
\hline G-III & 3 & 30 & 5 & 62.5 \\
\hline G-IV & 0 & 0 & 0 & 0 \\
\hline TOTAL & 10 & 100 & 8 & 100 \\
\hline
\end{tabular}


Sub Mucosal Fibrosis was in Arm A grade 1 (20\%), grade $2(50 \%)$ and grade $3(30 \%)$ Where as in Arm B grade $1(0 \%)$, grade $2(37.5 \%)$ and grade $3(62.5 \%)$. Chi-square $=0.9, \mathrm{df}=1, \mathrm{P}$ value $=0.1714$, not significant. [Table: 10]

\section{Discussion}

Dose per fraction along with overall treatment time are expected to be key factors in the outcomes of definitive radiotherapy for early glottis cancer. Radiotherapy treatment with short overall treatment times have the potential advantage of minimising the impact of accelerated repopulation. Overall treatment time is related to loco-regional control for head and neck cancers. An analysis of two trials suggested that in node negative larynx cancer an additional dose of $0.8 \mathrm{~Gy} /$ day is required to control tumour with increased treatment time ${ }^{[10]}$ Reduction in treatment time can be achieved by either hypofractionation or hyperfractionation with multiple treatments per day.

Our study shows that hypofractionated radiotherapy given to patients with Locally advance HNSCC, results in similar loco-regional control (LRC) compared to conventionally fractionated schedule. The addition of concurrent chemotherapy in locally advanced stage with this hypofractionated regimen, therefore, offers an attractive method to improve tumor control probability and maximize service productivity.

In the MARCH (meta-analysis of radiotherapy in carcinomas of the head and neck) of 15 phase III trials and 6,515 patients, there was $3.4 \%$ OS benefit at 5 years for altered fractionation as compared with conventional fractionation, with most benefit suggested for hyperfractionation. ${ }^{[11]}$ Concomitant chemotherapy with standard fractionation has repeatedly been shown to offer improved LRC and survival. Altered fractionation have been shown to be better than conventional radiation treatment schedules, and meta-analyses indicate that they confer about the same level of benefit in terms of LRC and survival.
Sanghera et al. Studied hypofractionated radiotherapy in patients with squamous cell cancer of the oral cavity, oropharynx, and hypopharynx and larynx, with dose of 55 Gy in 20 fractions with concurrent chemotherapy. 2-year Disease free survival rate was $68.6 \%$, 2-year local control rate was $75.4 \%$, the 2-year Overall survival rate was $71.6 \%$.

A study of radiotherapy schedule of hypofractionated intensity-modulated radiation therapy for early stage oropharyngeal cancer showed that moderately hypofractionated radiotherapy without chemotherapy for early oropharyngeal cancer is feasible, achieving high tumor control rates and reduced the salivary toxicity. ${ }^{[12]}$ Another prospective trial done by Bakst et al. In nasopharyngeal carcinoma a total of 70.2 Gy using 2.34 Gy per fraction for did not result in increased acute toxicities of the skin, mucous membranes, or salivary glands indicating that treatment was well-tolerated. Furthermore, no patients required significant treatment breaks nor did any patient require their chemotherapy to be withheld during radiation. Phase I dose escalation trial without concurrent chemotherapy indicated that 2.36 Gy per fraction for a total of 70.8 Gy was the maximal tolerable dose delivered to the gross tumor volume while using a simultaneous integrated boost for head and neck cancers.

In our study, we find that patients who achieve CR to treatment have not only improved loco-regional disease control, but also improved overall survival. Our finding underscores the great importance to reduce overall treatment time for HN cancers.

The follow-up of the present study was relatively short and prevents us from commenting on the long term disease free survival, overall survival, and a more comprehensive evaluation of the late toxicities too. limitation of our study was the relatively smaller sample size and consequently, subgroup analyses could not be materialised.

Use of hypofractionation is appealing for both health economics and patient perspectives. Hypofractionated radiotherapy reduces treatment 
time, number of fractions delivered and consequently cost; this eases treatment burden upon institutions. In addition, patients also benefits from the convenience of shorter schedules with fewer treatment visits required

\section{Conclusion}

The observations made in our study helped us arrive at a conclusion that Hypofractionated radiotherapy with concomitant cisplatin has a response comparable to the conventional chemoradiotherapy regimen with not significantly higher cases of oral mucositis. But the need of the our is, that studies with larger sample sizes and longer follow-up should be instituted for further validation of the feasibility of hypofractionated radiotherapy and to get significant results so that we are able to consider hypofractionated radiotherapy as a routine practice in treatment of loco-regionally advanced oral cavity and oropharyngeal carcinomas in future.

The unique features of our treatment schedule took advantage of reduced overall treatment time by three week to overcome the effect of accelerated tumor repopulation which is a major contributor in treatment failure. This was translated in improved tumor control rates as compared to conventional fractionation without a significant increase in normal tissue toxicity. Hypofractionated radiation plus concurrent 3 weekly cisplatin is a feasible schedule in patients with locally advanced head and neck cancer, with moderate efficacy and acceptable toxicity particularly in limited-resource settings.

Hypofractionation is not inferior to conventional fractionation in term of therapeutic effect, therefore in a busy patients setup like our, hypofractionation is a feasible option acute toxicity in both arm comparable but for late toxicity need longer follow up.

\section{References}

1. GLOBOCAN 2018, New Global Cancer Data:
2. Krstevska V. Radiotherapy and chemotherapy in locally advanced head and neck squamous cell carcinoma. J BUON. 2009;14:361-73.

3. Fu KK. Biological basis for the interaction of chemotherapeutic agents and radiation therapy. Cancer. 55:2123.1985.

4. Maciejewski B, Preuss-Bayer G, Trott KR.The influence of the number of fractions and overall treatment time on local control and late complication rate in squamous cell carcinoma of the larynx. Int J Radiat Oncol Biol Phys. 1983;9:321-328.

5. Withers, H.R., Taylor, J.M., Maciejewski, B. The hazard of accelerated tumor clonogen repopulation during radiotherapy ActaOncol. 1988;27:131-146.

6. Withers H, Taylor J, Maciejewski B: The hazard of accelerated tumor clonogen repopulation during radiotherapy. Acta Oncol 27:131-146, 1988.

7. Withers H, Peters L, Taylor J, et al: Local control of carcinoma of the tonsil by radiation therapy: An analysis of patterns of fractionation in nine institutions. Int $\mathbf{J}$ Radiat Oncol Biol Phys 33:549-562, 1995.

8. Sanghera P, McConkey C, Ho KF, Glaholm J, Hartley A. Hypofractionated accelerated radiotherapy with concurrent chemotherapy for locally advanced squamous cell carcinoma of the head and neck. Int J Radiat Oncol Biol Phys 2007;67:1342-51.

9. Somnath Roy, Chandrani Mallik, Suman Ghorai1, Avijit Hazra, Anup Majumdar Hypofractionated versus conventional radiotherapy with or without chemotherapy in head and neck cancer: A comparative study. Clin Cancer Investig J 2015; 4 : 1406

10. Overgaard J, Hansen HS, Specht L, et al. Five compared with six fractions per week of conventional radiotherapy of squamouscell carcinoma of head and neck: DAHANCA6\&7 randomised control trial. Lancet 2003;362:933-940 
11. Bourhis J, Overgaard J, Audry H, Ang KK, Saunders M, Bernier J, et al. Hyperfractionated or accelerated radiotherapy in head and neck cancer: A meta-analysis. Lancet 2006;368:843-54.

12. Castellsague $X$, Alemany L, Quer M, Halec G, Quiros B, Tous S, et al. (2016) HPV Involvement in Head and Neck Cancers: Comprehensive Assessment of Biomarkers in 3680 Patients. J Natl Cancer Inst, 108(6). 